\title{
Prevalence of premenstrual syndrome and dysmenorrhea among medical students and its impact on their college absenteeism
}

\author{
Arshia Syed, Smitha B. Rao*
}

Department of Obstetrics and Gynecology, Yenepoya Medical College, Mangalore, Karnataka, India

Received: 25 February 2020

Accepted: 03 March 2020

*Correspondence:

Dr. Smitha B. Rao,

E-mail: arshiasyed3@gamil.com

Copyright: (C) the author(s), publisher and licensee Medip Academy. This is an open-access article distributed under the terms of the Creative Commons Attribution Non-Commercial License, which permits unrestricted non-commercial use, distribution, and reproduction in any medium, provided the original work is properly cited.

\section{ABSTRACT}

Background: Dysmenorrhea and premenstrual syndrome are two most common gynaecological problem leading to college absenteeism seen among female medical students. Aim of the study was to evaluate the factors associated and prevalence of dysmenorrhoea and PMS and its effects on the quality of life, particularly absenteeism from college in female medical students. The health care profession has an obligation to provide and to promote education on menstruation and related subjects.

Methods: This is a prospective study, conducted on 100 MBBS students studying in a medical college at Mangalore. All participants were given a preformed questionnaire to complete. Dysmenorrhea was assessed based on WaLiDD scoring system. Diagnosis of PMS in the present study was made according to diagnosis criteria proposed by American College of obstetrician and gynecology. The severity of their condition was assessed based on their absenteeism from college/classes.

Results: The average age of the participants was 21 year \pm 1 year. The prevalence of dysmenorrhea was $45 \%$ and that of the pre-menstrual syndrome was $68 \%$. Pre-menstrual syndrome $(p=0.05)$ is significantly associated with overweight, obesity and physical inactivity but not the same for dysmenorrhea. $73 \%$ and $60 \%$ of students consumed junk food suffered from PMS and dysmenorrhea respectively, $40 \%$ of students with dysmenorrhea reported limitation of daily activities and significantly associated with college absenteeism $(p=0.005)$. The most frequent somatic symptom of PMS in this study was breast tenderness (41\%) and affective symptom was irritability (35\%).

Conclusions: Dysmenorrhea and PMS is highly prevalent among female medical students; it is related to college/class absenteeism. Unhealthy and sedentary lifestyle could be the attributing factors which has to be addressed by health education in order to improve the quality of life and academic performance by the medical students.

Keywords: Absenteeism, Body mass index, Dysmenorrhea, Premenstrual syndrome

\section{INTRODUCTION}

Dysmenorrhoea is defined as painful menstrual cramps of uterine origin. Two categories of dysmenorrhoea are defined, primary and secondary. Primary dysmenorrhea usually starts around the onset of menstruation and may continue for 8 hours to 3 days. A combination of factors that are postulated to be the contributing agents are increase in synthesis and secretion of prostaglandin F2 alpha, vasopressin and oxytocin, stimulation of the C type of pain fibres. Dysmenorrhea has various detrimental effects like work absenteeism, interference with daily activities, limitation in socialization, and higher intake of medications. NSAID given to reduce the discomfort of dysmenorrhea can increase the risk of heart attack or stroke, stomach ulcers, and bleeding, kidney, liver, and heart failure, anemia, asthma attacks and allergic reactions. In addition, stomach pain, diarrhoea, 
constipation, heartburn, dizziness, nausea, and vomiting are reported as the mild to moderate side effects of the consumption of NSAIDs. ${ }^{1}$

Premenstrual syndrome (PMS) is used to describe physical, cognitive, affective and behavioural symptoms that occur cyclically during the luteal phase of the menstrual cycle and resolve quickly at or within a few days of the onset of menstruation. ${ }^{2}$ ACOG published the diagnostic criteria for PMS. It was considered if at least one of the 6 affective and one of the 4 somatic symptoms was reported five days prior to the onset of menses in the three prior menstrual cycles and ceased within four days of onset of menses. Somatic symptoms include bloating sensation, breast swelling and pain, pelvic pain, head ache, skin disorders and changes in bowel habits. ${ }^{3}$ Psychosocial symptoms like irritability, aggressiveness, depression, anxiety, inability to concentrate, hypersomnia or insomnia, change in appetite, specific food craving, change in libido and poor coordination. ${ }^{4}$

The menstrual function is deemed to be one of the factors reflecting the functional potentiality of women and that may be affected by stress. There is also a growing evidence of an association between psychosocial stress and menses-associated health problems in women. ${ }^{5}$

\section{METHODS}

Relevant data was collected from female medical students of our medical college by excluding the candidates as per exclusion criteria. Written informed consent was taken from all patients enrolled in the study. Background information included was age, course, BMI, socioeconomic status, dietary habits, physical exercise, stress, family history of dysmenorrhea and PMS. Menstrual cycle related questions elucidated frequency, regularity, duration of flow and volume of flow per cycle. Dysmenorrhea was assessed based on WaLiDD scoring system. Diagnosis of PMS in the present study was made according to diagnosis criteria proposed by American College of obstetrician and gynecology. The severity of their condition was assessed based on their absenteeism from college/classes.

\section{Inclusion criteria}

- Females who were between the age of 18 and 25 years enrolled for MBBS course at our Medical
College Hospital, had regular periods for last 3 months before start of study and who consented for voluntary participation were included.

\section{Exclusion criteria}

- Female using hormonal tablets, or who had metrorrhagia, menometrorrhagia were excluded.

\section{Statistical analysis}

Data analysis by statistical package for social science (SPSS), descriptive statistic reported as mean and standard deviation for continuous variable. Frequency, proportion as categorical variables, qualitative, education, occupation socioeconomic status.

\section{RESULTS}

Figure 1 shows that majority of the students were in the age group of $21 \pm 1$ year.

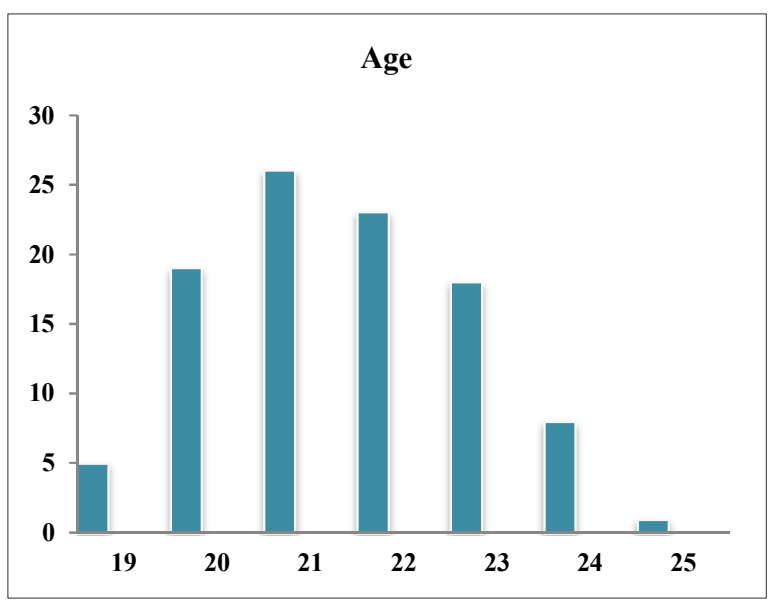

Figure 1: Age.

Table 1: Prevalence.

\begin{tabular}{|ll|l|}
\hline & Yes & No \\
\hline Dysmenorrhea & 45 & 55 \\
\hline PMS & 68 & 32 \\
\hline
\end{tabular}

As inferred by Table 1, prevalence of dysmenorrhea is $45 \%$ and that of PMS is $68 \%$.

Table 2: Dysmenorrhea and PMS in relation to BMI.

\begin{tabular}{|c|c|c|c|}
\hline & $\begin{array}{l}\text { Under weight } \\
(\mathrm{BMI}<18) \mathrm{n}=13\end{array}$ & $\begin{array}{l}\text { Normal } \\
\text { (BMI 18-24.99) } n=59\end{array}$ & $\begin{array}{l}\text { Overweight/obesity } \\
(\text { BMI }>25) n=41\end{array}$ \\
\hline Students with PMS & 6 & 40 & $22(\mathrm{p}=0.05)$ \\
\hline Students with dysmenorrhoeal & 7 & 23 & 15 \\
\hline
\end{tabular}


Table 2 concludes that PMS $(\mathrm{p}=0.05)$ is significantly associated with overweight and obesity but the same doesn't hold good for dysmenorrhea i.e., not significant $(\mathrm{p}=0.93)$.

Table 3 denotes that among the students doing any form of physical activity, $46 \%$ reported PMS whereas $81 \%$ of the students who were not involved in physical exercise reported PMS. The chi-square statistic is 14.0225 . The $\mathrm{p}$ value is 0.0001 . Significant at $p<0.05$. The $p$ value of 0.001 suggests a strong association between lack of physical activity and PMS.

Table 3: Association between physical activity and PMS.

\begin{tabular}{|l|ll|}
\hline & Physical activity & No physical activity \\
\hline PMS & 18 & 50 \\
\hline No PMS & 21 & 11 \\
\hline
\end{tabular}

Table 4: Association between physical activity and dysmenorrhoea.

\begin{tabular}{|l|l|l|}
\hline & $\begin{array}{l}\text { Physical } \\
\text { activity }\end{array}$ & $\begin{array}{l}\text { No physical } \\
\text { activity }\end{array}$ \\
\hline Dysmenorrhea & 19 & 25 \\
\hline No dysmenorrhea & 24 & 40 \\
\hline
\end{tabular}

Among the students doing any form of physical activity, $46 \%$ reported PMS where as $81 \%$ of the students who were not involved in physical exercise reported PMS. The chi-square statistic is 14.0225 . The $\mathrm{p}$ value is 0.0001 . Significant at $\mathrm{p}<0.05$. The $\mathrm{p}$ value of 0.001 suggests a strong association between lack of physical activity and PMS.

Table 4 shows no significant association between physical activity and dysmenorrhoea $\mathrm{p}=0.3$.

Table 5: Association between food habits and PMS.

\begin{tabular}{|l|ll|}
\hline & Junk food & Healthy food \\
\hline PMS & 22 & 23 \\
\hline No PMS & 8 & 47 \\
\hline
\end{tabular}

Table 5 interprets that out of 30 students who had frequent junk food as part of their dietary habit, $73.3 \%$ had pre-menstrual syndrome as compared to $32.8 \%$ of students who did not consume junk food frequently. Thus, the diet pattern of consuming fast foods frequently is significantly associated with pre-menstrual syndrome. The $\mathrm{p}$ value is 0.000193 , significant at $\mathrm{p}<0.05$.

Table 6: Association between food habits and dysmenorrhea.

\begin{tabular}{|l|l|l|}
\hline & Junk food & Healthy food \\
\hline Dysmenorrhea & 18 & 20 \\
\hline No dysmenorrhoeal & 12 & 50 \\
\hline
\end{tabular}

Table 6 analyses the association between the diet pattern and dysmenorrhoea. Out of 30 students having frequent fast food habits, $60 \%$ had dysmenorrhoea. Therefore, consuming fast foods frequently is significantly associated with dysmenorrhoea.

Table 7 highlights that out of the 45 students who had dysmenorrhea, $40 \%$ of them were absent from college due to the severity in dysmenorrhea. Out of which 9 had mild dysmenorrhea, 6 had moderate dysmenorrhea and 3 had severe dysmenorrhea.

Table 7: Association between severity of dysmenorrhea and college absenteeism.

\begin{tabular}{|l|l|ll|}
\hline & Mild & Moderate & Severe \\
\hline College absenteeism & 9 & 6 & 3 \\
\hline No college absenteeism & 18 & 8 & 1 \\
\hline
\end{tabular}

Table 8: PMS symptoms (affective symptoms).

\begin{tabular}{|lll|}
\hline & Number & Percentage \\
\hline Depression & 8 & $11.76 \%$ \\
\hline Anger outbursts & 12 & $17.64 \%$ \\
\hline Irritability & 24 & $35.29 \%$ \\
\hline Anxiety & 10 & $14.7 \%$ \\
\hline Confusion & 9 & $13.23 \%$ \\
\hline Social withdrawal & 5 & $7.35 \%$ \\
\hline
\end{tabular}

Table 9: PMS symptoms (somatic symptoms).

\begin{tabular}{|c|c|c|}
\hline & Number & Percentage \\
\hline Breast tenderness & 28 & $41.17 \%$ \\
\hline Abdominal bloating & 18 & $26.47 \%$ \\
\hline Headache & 14 & $20.58 \%$ \\
\hline Swelling of extremities & 8 & $11.76 \%$ \\
\hline
\end{tabular}

Table 8 and 9 interprets that the most frequent somatic symptom of PMS in this study was breast tenderness (41\%) and affective symptom was irritability (35\%). Other symptoms such as abdominal bloating (26\%), headache $(14 \%)$, swelling of the extremities (11.7\%), angry outbursts (17\%), depression (11.7\%), anxiety $(14.7 \%)$, confusion $(13.2 \%)$, and social withdrawal (7.3\%) were also present in significant number of participants.

Out of the 45 students who had dysmenorrhea, $40 \%$ of them were absent from college due to the severity in dysmenorrhea. Out of which 9 had mild dysmenorrhea, 6 had moderate dysmenorrhea and 3 had severe dysmenorrhea.

The most frequent somatic symptom of PMS in this study was breast tenderness (41\%) and affective symptom was irritability (35\%). Other symptoms such as abdominal bloating $(26 \%)$, headache $(14 \%)$, swelling of the extremities $(11.7 \%)$, angry outbursts $(17 \%)$, depression $(11.7 \%)$, anxiety $(14.7 \%)$, confusion $(13.2 \%)$, and social 
withdrawal (7.3\%) were also present in significant number of participants.

\section{DISCUSSION}

PMS is defined as cyclic physical and behavioral symptoms that appear in the days preceding menses and interfere with work or lifestyle, followed by a symptomfree interval. Premenstrual dysphoric disorder (PMDD) describes a severe form of PMS. Primary dysmenorrhea is associated with ovulatory cycles and results from myometrial contractions, in the absence of demonstrable disease. The health care profession has an obligation to provide and to promote education on menstruation and related subjects. ${ }^{6}$

Premenstrual symptoms are very common, reported by up to $75 \%$ of women with regular menstrual cycles. Among female adolescents, pre-menstrual syndrome and dysmenorrhea are the commonest gynecologic disorders presenting to health care professionals today.

In this study conducted on a total of 100 students, the prevalence of PMS is $68 \%$ and of dysmenorrhea is $45 \%$. This is comparable to another study done by Anand et al in which out of 300 students, $67 \%$ had pre-menstrual syndrome and $51 \%$ had dysmenorrhoea. ${ }^{7}$ Similarly an Indian study conducted by Raval $\mathrm{CM}$ et al, found a prevalence rate of $18.4 \%$ among college students. A higher prevalence rate of $82.81 \%$ was found in a study conducted at Riyadh.

When strictly defined based on prospective symptom diaries, clinically significant PMS occurs in $20-30 \%$ and PMDD affects $2-8 \%$ of women. As per the present study, the most frequent somatic symptom in this study was breast tenderness (41\%) and affective symptom was irritability $(35 \%)$. Other symptoms such as abdominal bloating $(26 \%)$, headache $(14 \%)$, swelling of the extremities $(11.7 \%)$, angry outbursts $(17 \%)$, depression $(11.7 \%)$, anxiety $(14.7 \%)$, confusion $(13.2 \%)$, and social withdrawal $(7.3 \%)$ were also present in significant number of participants. Out of the 45 students who had dysmenorrhea, $40 \%$ of them were absent from college due to the severity in dysmenorrhea. Out of which 9 $(50 \%)$ had mild dysmenorrhea, $6(33.3 \%)$ had moderate dysmenorrhea and $3(16.6 \%)$ had severe dysmenorrhea.

The prevalence of PMS was reported to be $65 \%$ in a study done by Geeta et al. The most common somatic symptom was body pain (52\%) and the most common affective symptom was irritability (50\%). Only $12 \%$ of individuals with PMS become absent in class and $32 \%$ avoid joining social functions. ${ }^{8}$ Primary dysmenorrhea is one of the commonest reasons of class absenteeism in young females. In total, $8.7 \%$ of students reported college absenteeism in a study done by Rafiq et al, due to severe dysmenorrhea, whereas $54.5 \%$ of the students mentioned that dysmenorrhea negatively affected their studies and daily activities. These results are in line with previous studies which highlight that educational performance of most of dysmenorrhea females $(60.4 \%)$ is affected due to class absentees, loss of concentration, lack of focus in exams and inability to do homework. Moreover, Minaleshewa et al, observed that $63 \%$ of their PMS respondents encountered social withdrawal and 51.4\% showed decrease in academic performance. ${ }^{9}$

In this study concludes that pre-menstrual syndrome ( $\mathrm{p}=$ 0.05 ) is significantly associated with overweight and obesity but the same doesn't hold good for dysmenorrhea i.e; not significant $(p=0.93)$ The mean BMI of the students was $21.69 \pm 3.27 \mathrm{~kg} / \mathrm{m}^{2}$ in a study done by Charu et al, $67.1 \%$ of the women had a normal BMI. Although not significantly associated, it was found that participants who were underweight were 0.002 times less likely, whereas those overweight and obese are more likely to suffer from dysmenorrhea when compared to participants with normal BMI. ${ }^{10}$ Menstrual problems are generally perceived as only major health concerns and thus irrelevant to the public health agenda. Data on the frequency of menstrual dysfunction and its impact on health status, quality of life and social integration among women in developing countries are scant.

The WaLIDD score contained three frequently used criteria identified in the definitions of dysmenorrhea present in the literature: days of pain (D), work ability (Wa), and anatomical region of pain location (L). ${ }^{11}$ Study reported that about $16 \%$ of the students had symptoms which were severe enough for them to be absent from college. In several studies of young women, rates of absenteeism ranged from $34 \%$ to $50 \%$. Other studies showed that up to $40 \%$ of female students in their study reported that their ability to perform work was affected. ${ }^{7}$ Similar studies among female high school adolescents showed that the majority of female adolescents identified dysmenorrhea and PMS as problems that significantly affected their academic performance.

\section{CONCLUSION}

Dysmenorrhea and PMS is highly prevalent among female medical students, it is related to college/class absenteeism. Unhealthy and sedentary lifestyle could be the attributing factors which has to be addressed by health education in order to improve the quality of life and academic performance by the medical students.

Funding: No funding sources

Conflict of interest: None declared

Ethical approval: The study was approved by the Institutional Ethics Committee

\section{REFERENCES}

1. Tolossa F, Bekele M. Prevalence, impacts and medical managements of premenstrual syndrome among female students: cross-sectional study in college of health sciences, Mekelle University, 
Mekelle, Northern Ethiopia. BMC Women's Health. 2014;14(1):52.

2. Badkur D, Singh S, Chauhan D, Sinha A. Premenstrual syndrome and its association with menstrual profile among female students of colleges in Ujjain city, Madhya Pradesh, India. Inter J Res Med Sci. 2018;6(8):2726.

3. Aryal S, Thapa B, Pant S. Premenstrual syndrome and premenstrual dysphoric disorder in medical and nursing students of a tertiary care teaching hospital in Nepal. Nepal J Obstet Gynaecol. 2018;12(1):12-6.

4. Balaha M, Amr M, Moghannum M, Muhaida N. The phenomenology of premenstrual syndrome in female medical students: a cross sectional study. Pan African Med J. 2010;5(1):44641.

5. Raval C, Panchal B, Tiwari D, Vala A, Bhatt R. Prevalence of premenstrual syndrome and premenstrual dysphoric disorder among college students of Bhavnagar, Gujarat. Indian J Psych. 2016;58(2):164.

6. Speroff L, Fritz M. Clinical gynecologic endocrinology and infertility. $8^{\text {th }}$ ed. Philadelphia: Lippincott Williams and Wilkins; 2005;567-573.

7. Lakshmi S, Priy MA, Saraswathi I, Saravanan A, Ramamchandran C. Prevalence of premenstrual syndrome and dysmenorrhoea among female medical students and its association with college Absenteeism. Inter J Biol Med Res. 2011;2(4):10116.
8. Shamnani G, Gupta V, Jiwane R, Singh S, Tiwari S, Bhartiy S. Prevalence of premenstrual syndrome and premenstrual dysphoric disorder among medical students and its impact on their academic and social performance. Nat J Physiol Pharma Pharmacol. 2018;8(9):1205.

9. Rafique N, Al-Sheikh M. Prevalence of primary dysmenorrhea and its relationship with body mass index. J Obstet Gynaecol Res. 2018;44(9):1773-8.

10. Shrotriya C, Ray A, George A, Ray S. 'Menstrual characteristics' and 'prevalence and effect of dysmenorrhea' on quality of life of medical students. Inter J Collab Res Int Med Pub Health. 2012;4(4):276-94.

11. Teherán A, Pineros L, Pulido F, Mejía Guatibonza M. WaLIDD score, a new tool to diagnose dysmenorrhea and predict medical leave in university students. Inter J Women's Health. 2018;10:35-45.

Cite this article as: Syed A, Rao SB. Prevalence of premenstrual syndrome and dysmenorrhea among medical students and its impact on their college absenteeism. Int J Reprod Contracept Obstet Gynecol 2020;9:1377-81. 